\title{
Mucocutaneous lesions in free-ranging Atlantic bottlenose dolphins Tursiops truncatus from the southeastern USA
}

\author{
Gregory D. Bossart ${ }^{1,2, *}$, Adam M. Schaefer ${ }^{3}$, Stephen McCulloch ${ }^{3,6}$, Juli Goldstein ${ }^{3,6}$, \\ Patricia A. Fair ${ }^{4}$, John S. Reif \\ ${ }^{1}$ Georgia Aquarium, 225 Baker Street, NW, Atlanta, Georgia 30313, USA \\ ${ }^{2}$ Division of Comparative Pathology, Miller School of Medicine, University of Miami, PO Box 016960 (R-46) Miami, Florida 33101, USA \\ ${ }^{3}$ Harbor Branch Oceanographic Institute at Florida Atlantic University, 5600 US 1 North, Ft. Pierce, Florida 34946, USA \\ ${ }^{4}$ National Oceanic and Atmospheric Administration, National Ocean Service, Center for Coastal Environmental Health \\ and Biomolecular Research, 219 Fort Johnson Rd, Charleston, South Carolina 29412, USA \\ ${ }^{5}$ Department of Environmental and Radiological Health Sciences, College of Veterinary Medicine and Biomedical Sciences, \\ Colorado State University, Fort Collins, Colorado 80523, USA \\ ${ }^{6}$ Present address: Protect Wild Dolphins Alliance, 2046 Treasure Coast Plaza, Vero Beach, Florida 32960, USA
}

\begin{abstract}
Mucocutaneous lesions were biopsied from free-ranging Atlantic bottlenose dolphins Tursiops truncatus inhabiting the Indian River Lagoon (IRL), Florida, and estuarine waters of Charleston (CHS), South Carolina, USA, between 2003 and 2013. A total of 78 incisional biopsies from 58 dolphins ( $\mathrm{n}=43 \mathrm{IRL}, \mathrm{n}=15 \mathrm{CHS}$ ) were examined. Thirteen dolphins had 2 lesions biopsied at the same examination, and 6 dolphins were re-examined and re-biopsied at time intervals varying from 1 to 8 yr. Biopsy sites included the skin $(n=47)$, tongue $(n=2)$, and genital mucosa $(n=$ 29). Pathologic diagnoses were: orogenital sessile papilloma $(39.7 \%)$, cutaneous lobomycosis $(16.7 \%)$, tattoo skin disease (TSD; $15.4 \%)$, nonspecific chronic to chronic-active dermatitis $(15.4 \%)$, and epidermal hyperplasia $(12.8 \%)$. Pathologic diagnoses from dolphins with 2 lesions were predominately orogenital sessile papillomas $(\mathrm{n}=9)$ with nonspecific chronic to chronic-active dermatitis $(n=4)$, TSD $(n=3)$, lobomycosis $(n=1)$, and epidermal hyperplasia $(n=1)$. Persistent pathologic diagnoses from the same dolphins re-examined and re-biopsied at different times included genital sessile papillomas $(n=3)$, lobomycosis $(n=2)$, and nonspecific dermatitis $(n=2)$. This is the first study documenting the various types, combined prevalence, and progression of mucocutaneous lesions in dolphins from the southeastern USA. The data support other published findings describing the health patterns in dolphins from these geographic regions. Potential health impacts related to the observed suite of lesions are important for the IRL and CHS dolphin populations, since previous studies have indicated that both populations are affected by complex infectious diseases often associated with immunologic disturbances and anthropogenic contaminants.
\end{abstract}

KEY WORDS: Papilloma - Lobomycosis - Lacazia loboi - Tattoo skin disease - Dermatitis · Hyperplasia $\cdot$ Zoonosis $\cdot$ Cetacean $\cdot$ Pathology

\section{INTRODUCTION}

Diseases of the skin and mucous membranes in domestic mammals may be infectious or noninfectious in etiology (Ginn et al. 2007). Infectious mucosal and skin disorders may be of bacterial, viral, mycotic,

\footnotetext{
*Corresponding author: gbossart@georgiaaquarium.org
}

or parasitic etiology. Noninfectious mucosal diseases and dermatoses include neoplastic, hormonal, immune-mediated, and traumatic conditions (Gross et al. 2005). Additionally, mucocutaneous lesions may represent primary disease or be secondary to systemic disease conditions (Bossart et al. 2003, 2013, 
Ginn et al. 2007). As such, understanding mucocutaneous disease from a pathologic perspective can provide important information for individual and population health of marine mammals. Mucocutaneous lesions in Atlantic bottlenose dolphins Tursiops truncatus have been described in stranded and managed-care animals, but little information is available regarding the etiopathogenesis of these conditions in free-ranging populations. Photo-identification studies have been used to document the gross appearance of cutaneous lesions in free-ranging dolphin populations (Wilson et al. 1999, 2000, Van Bressem et al. 2003, 2007b, 2009b, Bearzi et al. 2009, Maldini et al. 2010, Hart et al. 2012). However, photo-identification studies do not provide a definitive morphologic or etiologic diagnosis of cutaneous lesions and are of limited use for documenting the presence of mucosal lesions. Alternatively, free-ranging dolphin health assessments that involve the temporary capture and release of animals allow the pathologic evaluation of mucocutaneous lesions via biopsy as well as the collection of associated clinicopathologic data that are useful for the determination of individual and population health. Additionally, in some geographic locations, health assessment studies allow for serial sampling of the same dolphins, which provides information about lesion progression over time and epidemiologic incidence data that become important for evaluating population health. Unfortunately, opportunities for longitudinal dolphin health assessment studies have been limited historically because of economic and logistical complexities. In this study, we report the pathologic findings from mucocutaneous biopsies from a long-term, free-ranging dolphin health assessment project from the southeastern US. In particular, for the first time we examine the various pathologic diagnoses, combined prevalence, and progression of mucocutaneous lesions of bottlenose dolphins from this geographic region.

\section{MATERIALS AND METHODS}

The Atlantic bottlenose dolphin Health and Environmental Risk Assessment (HERA) project was initiated as a multidisciplinary, integrated collaborative effort in 2003 to assess individual and population health in 2 southeast estuarine coastal regions of the USA: Charleston, South Carolina (CHS), and the Indian River Lagoon, Florida (IRL) (Bossart et al. 2006). In part, the goals of the project are to develop standardized tools for health and risk assessment, and to explore associations between health status and environmental stressors. Bottlenose dolphins serve as a sentinel species for monitoring the health of the environment and may provide valuable information for evaluating the relationship between exposure to biological and chemical agents and adverse health effects for these populations (Bossart 2011).

The IRL is a shallow-water ecosystem that comprises $40 \%$ of Florida's central east coast. The lagoon is an aggregate of 3 estuarine water bodies: the Indian and Banana Rivers and the Mosquito Lagoon that extends $250 \mathrm{~km}$ from Ponce De Leon Inlet in the north to Jupiter Inlet in the south. The CHS site is an estuarine environment in the central region of South Carolina's coastal zone that includes the Charleston Harbor, as well as portions of the Ashley River, Cooper River, Wando River, and Stono River estuary. Photo-identification survey data indicate that dolphins at both sites display long-term residency patterns and site fidelity, with an estimated population of 1000 dolphins for the IRL and approximately 910 dolphins in fall and 364 in winter for CHS (Zolman 2002, Mazzoil et al. 2008, Speakman et al. 2010).

Dolphins in this study were captured, biopsied, and released in the IRL during June of 2003 to 2007 and June of 2010 to 2012 and in the waters near CHS during August of 2003 to 2005 and 2013. Sampling was conducted in specific areas within each site based on population abundance estimates obtained from photo-identification surveys. Standard operating protocols and techniques for sample collection are described in detail elsewhere (Fair et al. 2006). Age was estimated by counting post-natal dentine layers in an extracted tooth (Hohn et al. 1989). In instances when a tooth was unobtainable, age was estimated from total body length ranges established for the species (Geraci \& Lounsbury 2005). For this study, adults were defined as dolphins $6 \mathrm{yr}$ of age or older and subadults from 3.5 to $5.9 \mathrm{yr}$, as described previously (Bossart et al. 2005, 2008). Dolphin calves were not included in the study, as this age group was not permitted to be captured under capture permit restrictions.

Incisional biopsies were aseptically obtained following $2 \%$ lidocaine hydrochloride local anesthesia from dolphins observed to have skin, genital, and/or oral lesions during physical examination. Tissues were placed in $10 \%$ neutral buffered formalin, routinely processed, embedded in paraffin, sectioned at $5 \mu \mathrm{m}$, and stained with hematoxylin and eosin for examination by light microscopy (Bossart et al. 2003). Special stains used were Gomori's methenamine silver and Brown and Brenn. Electron microscopy and molecular diagnostic testing were not done. All 
methods used in HERA for capture and sample collection were approved under National Marine Fisheries Service Scientific Research Permit Nos. 9981678 and 14352-02 issued to G. Bossart and IACUC protocol number A10-13 issued by Florida Atlantic University .

\section{RESULTS}

The date of examination, age, sex, capture site, biopsy site, and pathologic diagnosis are summarized in Table 1. In total, 78 incisional biopsies from 58 dol- phins were examined and form the basis of this study. Adult male dolphins comprised the majority of cases in all diagnostic categories for the IRL and CHS. Biopsy sites included the skin $(\mathrm{n}=47)$, tongue $(\mathrm{n}=2)$, and genital mucosa $(\mathrm{n}=29)$. In decreasing prevalence, pathologic diagnoses comprised orogenital sessile papilloma $(39.7 \%)$, cutaneous lobomycosis $(16.7 \%)$, tattoo skin disease $\left(\mathrm{TSD}_{1} 15.4 \%\right)$, nonspecific chronic to chronic-active dermatitis $(15.4 \%)$, and epidermal hyperplasia (12.8\%).

Genital sessile papillomas $(n=29)$ were found on the penis, external male genital mucosa, or the external female genital mucosa (vulva) beneath the geni-

Table 1. Mucocutaneous lesions from bottlenose dolphins Tursiops truncatus from the southeastern USA, 2003-2013. Bold: individual dolphins with multiple lesions biopsied at the same examination; gray shading: individual dolphins biopsied on more than 1 occasion. CHS: Charleston, South Carolina; IRL: Indian River Lagoon, Florida; TSD: tattoo skin disease

\begin{tabular}{|c|c|c|c|c|c|c|}
\hline ID & $\begin{array}{c}\text { Date } \\
(\mathrm{mo} / \mathrm{d} / \mathrm{yr})\end{array}$ & $\begin{array}{l}\text { Age } \\
\text { (yr) }\end{array}$ & Sex & $\begin{array}{c}\text { Capture } \\
\text { site }\end{array}$ & $\begin{array}{l}\text { Biopsy } \\
\text { site }\end{array}$ & Diagnosis \\
\hline 801 & 8/11/2003 & 20 & $\mathrm{~F}$ & CHS & Skin & Dermatitis, hyperplastic, chronic, multifocal, mild to moderate \\
\hline 820 & $8 / 14 / 2003$ & 6.5 & $\mathrm{M}$ & CHS & Skin & Epidermis, hyperplasia, focal, moderate \\
\hline 824 & $8 / 15 / 2003$ & 10 & $\mathrm{M}$ & CHS & Skin & Epidermis, hyperplasia, focal, mild to moderate \\
\hline 848 & $8 / 12 / 2004$ & 6 & M & CHS & Genital mucosa & Sessile papilloma \\
\hline 859 & $8 / 2 / 2005$ & 9 & $\mathrm{~F}$ & CHS & Genital mucosa & Sessile papilloma \\
\hline 866 & $8 / 29 / 2013$ & 23 & $\mathrm{M}$ & $\mathrm{CHS}$ & Skin & Dermatitis, hyperplastic, chronic, superficial and perivascular, multifocal, moderate \\
\hline 867 & 8/3/2005 & 11 & $\mathrm{~F}$ & CHS & Genital mucosa & Sessile papilloma \\
\hline 868 & 8/8/2005 & 10 & $\mathrm{M}$ & CHS & Genital mucosa & Sessile papilloma \\
\hline 870 & $8 / 22 / 2003$ & Subadult ${ }^{\mathrm{a}}$ & M & CHS & Skin & Epidermis, hyperplasia, diffuse, moderate \\
\hline 890 & 8/18/2004 & 8 & $\mathrm{M}$ & CHS & Genital mucosa & Sessile papilloma \\
\hline 892 & $8 / 19 / 2004$ & 24 & $\mathrm{M}$ & CHS & Genital mucosa & Sessile papilloma \\
\hline 896 & $8 / 2 / 2005$ & 16 & M & CHS & Skin & Dermatitis, hyperplastic, chronic, superficial and perivascular, multifocal, mild to moderate \\
\hline 896 & $8 / 21 / 2013$ & 24 & M & CHS & Skin & Dermatitis, hyperplastic, chronic, superficial and perivascular, multifocal, mild to moderate \\
\hline 898 & $8 / 4 / 2005$ & 7 & M & CHS & Genital mucosa & Sessile papilloma \\
\hline 901 & $7 / 9 / 2003$ & 9 & $\mathrm{~F}$ & IRL & Skin & Epidermis, hyperplasia, focal, mild \\
\hline 913 & $7 / 14 / 2003$ & 26 & $\mathrm{~F}$ & IRL & Skin & Dermatitis, granulomatous, multifocal, severe, mycotic, lobomycosis \\
\hline 917 & $6 / 29 / 2005$ & 4 & $\mathbf{F}$ & IRL & Skin & TSD \\
\hline 917 & $6 / 29 / 2005$ & 4 & $\mathbf{F}$ & IRL & Genital mucosa & Sessile papilloma \\
\hline 920 & $7 / 10 / 2003$ & 10 & $\mathrm{M}$ & IRL & Skin & Dermatitis, hyperplastic, chronic, superficial and perivascular, multifocal, mild to moderate \\
\hline 921 & 7/17/2003 & Adult ${ }^{\mathrm{a}}$ & $\mathrm{F}$ & IRL & Skin & Dermatitis, granulomatous, multifocal, severe, mycotic, lobomycosis \\
\hline 929 & $6 / 22 / 2004$ & 9.5 & $\mathrm{~F}$ & IRL & Skin & Dermatitis, hyperplastic, chronic, multifocal, mild \\
\hline 935 & $6 / 23 / 2004$ & 10 & $\mathbf{F}$ & IRL & Skin & TSD \\
\hline 935 & $6 / 23 / 2004$ & 10 & F & IRL & Tongue & Sessile papilloma \\
\hline 936 & $6 / 28 / 2005$ & 14 & M & IRL & Genital mucosa & Sessile papilloma \\
\hline 936 & 6/18/2012 & 21 & $\mathrm{M}$ & IRL & Genital mucosa & Sessile papilloma \\
\hline 938 & $7 / 15 / 2003$ & 15 & $\mathrm{M}$ & IRL & Skin & Dermatitis, granulomatous, multifocal, mild, mycotic, lobomycosis \\
\hline 939 & $6 / 24 / 2004$ & 3.5 & $\mathbf{F}$ & IRL & Skin & TSD \\
\hline 939 & $6 / 24 / 2004$ & 3.5 & $\mathbf{F}$ & IRL & Genital mucosa & Sessile papilloma \\
\hline 941 & $6 / 24 / 2004$ & 12.5 & $\mathrm{~F}$ & IRL & Skin & TSD \\
\hline 943 & $6 / 24 / 2004$ & 11 & $\mathrm{~F}$ & IRL & Skin & TSD \\
\hline 945 & $6 / 24 / 2004$ & 11 & $\mathrm{~F}$ & IRL & Skin & TSD \\
\hline 946 & $7 / 16 / 2003$ & 17 & M & IRL & Skin & Dermatitis, granulomatous, multifocal, severe, mycotic, lobomycosis \\
\hline 946 & 6/30/2006 & 17 & $\mathbf{M}$ & IRL & Skin & Dermatitis, granulomatous, multifocal, severe, mycotic, lobomycosis \\
\hline 946 & $6 / 30 / 2006$ & 17 & $\mathbf{M}$ & IRL & Genital mucosa & Sessile papilloma \\
\hline 947 & $6 / 29 / 2004$ & 10 & $\mathrm{~F}$ & IRL & Skin & TSD \\
\hline 950 & $7 / 1 / 2004$ & 27 & M & IRL & Skin & Dermatitis, granulomatous, multifocal, severe, mycotic, lobomycosis \\
\hline 952 & 7/18/2003 & 18 & $\mathbf{M}$ & IRL & Skin & TSD \\
\hline 952 & 7/18/2003 & 18 & $\mathbf{M}$ & IRL & Skin & Dermatitis, granulomatous, multifocal, severe, mycotic, lobomycosis \\
\hline 953 & $6 / 30 / 2004$ & Subadult ${ }^{\mathrm{a}}$ & $\mathrm{F}$ & IRL & Skin & Dermatitis, granulomatous, multifocal, severe, mycotic, lobomycosis \\
\hline 953 & $6 / 30 / 2007$ & Adult $^{\mathrm{a}}$ & $\mathrm{F}$ & IRL & Skin & Dermatitis, granulomatous, multifocal, severe, lobomycosis \\
\hline 959 & $7 / 1 / 2004$ & Adult ${ }^{\mathrm{a}}$ & $\mathbf{F}$ & IRL & Skin & Epidermis, hyperplasia, multifocal, mild \\
\hline 959 & $7 / 1 / 2004$ & Adult $^{\mathrm{a}}$ & $\mathbf{F}$ & IRL & Skin & Dermatitis, granulomatous, multifocal, severe, mycotic, lobomycosis \\
\hline 961 & $7 / 1 / 2004$ & Adult ${ }^{\mathrm{a}}$ & $\mathrm{F}$ & IRL & Skin & Dermatitis, granulomatous, multifocal, severe, mycotic, lobomycosis \\
\hline
\end{tabular}


Table 1. continued

\begin{tabular}{|c|c|c|c|c|c|c|}
\hline ID & $\begin{array}{c}\text { Date } \\
(\mathrm{mo} / \mathrm{d} / \mathrm{yr})\end{array}$ & $\begin{array}{l}\text { Age } \\
(\mathrm{yr})\end{array}$ & Sex & $\begin{array}{l}\text { Capture } \\
\text { site }\end{array}$ & $\begin{array}{l}\text { Biopsy } \\
\text { site }\end{array}$ & Diagnosis \\
\hline 962 & $6 / 21 / 2004$ & 16 & M & IRL & Skin & TSD \\
\hline 966 & $6 / 22 / 2004$ & 6 & M & IRL & Skin & TSD \\
\hline 973 & $6 / 22 / 2006$ & 8 & $\mathrm{~F}$ & IRL & Genital mucosa & Sessile papilloma \\
\hline 976 & 6/23/2004 & 8 & M & IRL & Tongue & Sessile papilloma \\
\hline 978 & $6 / 23 / 2004$ & 12 & $\mathbf{M}$ & IRL & Skin & TSD \\
\hline 978 & $6 / 23 / 2004$ & 12 & $\mathbf{M}$ & IRL & Skin & Epidermis, hyperplasia, multifocal, moderate \\
\hline 980 & 6/24/2004 & 9 & $\mathbf{M}$ & IRL & Skin & TSD \\
\hline 980 & $6 / 24 / 2004$ & 9 & $\mathbf{M}$ & IRL & Skin & Dermatitis, hyperplastic, chronic-active, multifocal, moderate \\
\hline 982 & $6 / 30 / 2004$ & 11 & M & IRL & Genital mucosa & Sessile papilloma \\
\hline 998 & $6 / 23 / 2005$ & 23 & M & IRL & Genital mucosa & Sessile papilloma \\
\hline $98 \mathrm{E}$ & $6 / 24 / 2010$ & 18 & $\mathrm{M}$ & IRL & Skin & Dermatitis, granulomatous, multifocal, mycotic, moderate, lobomycosis \\
\hline 8F8 & $8 / 27 / 2013$ & 17 & M & $\mathrm{CHS}$ & Genital mucosa & Sessile papilloma \\
\hline $8 \mathrm{~J} 2$ & $8 / 29 / 2013$ & 33 & M & CHS & Genital mucosa & Sessile papilloma \\
\hline $9 \mathrm{~A} 6$ & $6 / 28 / 2005$ & 6.5 & M & IRL & Genital mucosa & Sessile papilloma \\
\hline $9 \mathrm{CO}$ & $6 / 22 / 2006$ & 10.5 & $\mathbf{M}$ & IRL & Skin & Dermatitis, hyperplastic, chronic, multifocal, mild \\
\hline $9 \mathrm{CO}$ & $6 / 22 / 2006$ & 10.5 & $\mathbf{M}$ & IRL & Genital mucosa & Sessile papilloma \\
\hline $9 \mathrm{C} 8$ & $6 / 26 / 2006$ & 10.5 & M & IRL & Genital mucosa & Sessile papilloma \\
\hline 9D2 & $6 / 27 / 2006$ & 14 & M & IRL & Genital mucosa & Sessile papilloma \\
\hline $9 \mathrm{~V} 0$ & $6 / 27 / 2006$ & 15 & M & IRL & Skin & Dermatitis, granulomatous, multifocal, mycotic, moderate, lobomycosis \\
\hline $9 \mathrm{~V} 6$ & $6 / 29 / 2006$ & 18 & M & IRL & Skin & Epidermis, hyperplasia, focal, moderate \\
\hline $90 \mathrm{H}$ & $6 / 17 / 2011$ & 6 & $\mathbf{M}$ & IRL & Skin & Dermatitis, necrotizing, chronic-active, multifocal, moderate \\
\hline $90 \mathrm{H}$ & 6/17/2011 & 6 & $\mathbf{M}$ & IRL & Genital mucosa & Sessile papilloma \\
\hline $90 \mathrm{~K}$ & $6 / 27 / 2012$ & Adult $^{\mathrm{a}}$ & $\mathbf{M}$ & IRL & Skin & Dermatitis, hyperplastic, superficial, perivascular, chronic, multifocal, moderate \\
\hline $90 \mathrm{~K}$ & 6/27/2012 & Adult $^{\mathrm{a}}$ & $\mathbf{M}$ & IRL & Skin & Epidermis, hyperplasia, focal, mild \\
\hline $92 \mathrm{~F}$ & 6/13/2011 & 8.5 & M & IRL & Skin & Epidermis, hyperplasia, focal, moderate \\
\hline $92 \mathrm{~J}$ & $6 / 19 / 2012$ & 6 & $\mathbf{M}$ & IRL & Skin & Epidermis, hyperplasia, focal, moderate \\
\hline $92 \mathrm{~J}$ & 6/19/2012 & 6 & $\mathbf{M}$ & IRL & Genital mucosa & Sessile papilloma \\
\hline 96D & $6 / 21 / 2010$ & 23 & $\mathbf{M}$ & IRL & Skin & Dermatitis, chronic-active, multifocal, mild \\
\hline 96D & $6 / 21 / 2010$ & 23 & $\mathbf{M}$ & IRL & Genital mucosa & Sessile papilloma \\
\hline 96D & $6 / 17 / 2011$ & 24 & $\mathbf{M}$ & IRL & Skin & Dermatitis, chronic-active, multifocal, mild \\
\hline 96D & $6 / 17 / 2011$ & 24 & $\mathbf{M}$ & IRL & Genital mucosa & Sessile papilloma \\
\hline $98 \mathrm{~A}$ & $6 / 28 / 2007$ & 7 & M & IRL & Genital mucosa & Sessile papilloma \\
\hline $98 \mathrm{~A}$ & $6 / 23 / 2010$ & 10 & M & IRL & Genital mucosa & Sessile papilloma \\
\hline $98 \mathrm{C}$ & 6/18/2010 & 16 & M & IRL & Genital mucosa & Sessile papilloma \\
\hline 98D & $6 / 21 / 2010$ & 23 & M & IRL & Genital mucosa & Sessile papilloma \\
\hline
\end{tabular}

tal slit and were the most common mucocutaneous lesions found in IRL and CHS dolphins. Two oral sessile papillomas were located on the anteriodorsal aspect of the tongue. Grossly, lesions were focal to multifocal, irregular to circular, raised, soft, light pink to white, and sessile, ranging from 0.5 to $2 \mathrm{~cm}$ in diameter. The surface of these lesions appeared fissured or velvety and non-ulcerative. Microscopically, the orogenital lesions were characterized by focal sessile plaques composed of uniformly proliferating keratinocytes and occasionally dysplastic keratinocytes with broad rete ridge formation. Mild to moderate koilocytosis also was present in most cases. Attenuated dermal papillae containing capillaries sometimes separated the broad rete ridges. Inclusion bodies were not observed.

Grossly, cutaneous lobomycosis ( $\mathrm{n}=13$ ) was characterized by multifocal, firm, raised, white nodules and plaques usually on the leading edges of the dorsal and pectoral fins, the head, and the flukes, meas- uring from $1 \mathrm{~cm}$ to up to $30 \mathrm{~cm}$ in the broadest dimension. Many nodules had a verrucous appearance. Microscopically, the lesions were characterized by epidermal hyperplasia with associated multifocal dermal granulomas which often extended deep into the subcutaneous fat (blubber). The granulomas were comprised of primarily epithelioid macrophages, multinucleated giant cells and rarely lymphocytes and plasma cells which surrounded yeastlike structures with thick refractile walls measuring from 6 to $12 \mu \mathrm{m}$ in diameter. Methenamine silverstained sections of dermis demonstrated yeast-like structures arranged at various angles and in chains connected by tube-like bridges consistent with the ascomycete Lacazia loboi.

Grossly, TSD lesions ( $\mathrm{n}=12$ ) were typically randomly distributed, multifocal to coalescing ring to pinhole shaped, flat, soft, light gray, and nonulcerative, ranging from 0.3 to $1 \mathrm{~cm}$ in diameter. Lesions occasionally had a black punctiform stippled pattern 
resembling a tattoo. Microscopically, the stratum externum of the lesions was moderately hyperplastic and ventrally compressed the underlying stratum intermedium. Keratinocytes of the stratum intermedium were characterized by often marked cytoplasmic vacuolation and contained low variable numbers of spherical or irregularly shaped, pale, eosinophilic, intracytoplasmic inclusions. Inflammation was not present.

The lesions in the nonspecific chronic to chronicactive dermatitis diagnostic category $(\mathrm{n}=12)$ had a wide range of gross appearances but were typically randomly distributed, focal, irregular to circular, slightly raised, firm, gray to tan, and non-ulcerative, ranging from 0.5 to $1 \mathrm{~cm}$ in diameter. Microscopically, mild to moderate, multifocal, chronic $(n=8)$ to chronic-active $(\mathrm{n}=4)$ inflammation was typically present in the perivascular regions of the superficial dermis. Inflammatory cell infiltrates consisted primarily of lymphocytes and plasma cells in the chronic dermatitis cases and an admixture of neutrophils, macrophages, lymphocytes, and plasma cells in the chronic-active dermatitis cases. Concurrent epidermal hyperplasia $(\mathrm{n}=9)$ was also present with a microscopic pattern described below. One case had associated dermal necrosis. Additionally, the special histochemical stains used did not demonstrate causative organisms, including fungi. Inclusion bodies were not observed. The etiology of these lesions was not determined.

Epidermal hyperplasia lesions $(n=10)$ were focal, irregular to circular, soft, slightly raised, light gray, and randomly distributed, measuring from 0.5 to $1 \mathrm{~cm}$ in diameter. Microscopically, the lesions were characterized by mild to moderate, focal, uniform epidermal hyperplasia without an inflammatory component or keratinocyte cytoplasmic vacuolation. Superficial or deep epidermal projections were not present. Causative organisms and epithelial inclusion bodies were not observed.

Thirteen dolphins had 2 lesions biopsied at the same examination time. Pathologic diagnoses in this group were represented predominately by orogenital sessile papilloma $(n=9)$ with concurrent nonspecific dermatitis $(n=4), \operatorname{TSD}(n=3)$, lobomycosis $(n=1)$, and epidermal hyperplasia $(\mathrm{n}=1)$.

Six dolphins $(896,936,946,953,96 \mathrm{D}, 98 \mathrm{~A})$ were reexamined at $1 \mathrm{yr}(96 \mathrm{D}), 3 \mathrm{yr}(946,953,98 \mathrm{~A}), 7 \mathrm{yr}$ (936), and $8 \mathrm{yr}$ (896) time intervals (Table 1). Five of these dolphins $(896,936,946,953,98 \mathrm{~A})$ had a mucocutaneous lesion biopsied at each examination. One of the dolphins (96D) had 2 different lesions biopsied at the same exam time. Persistent pathologic diag- noses from dolphins biopsied at different times included genital sessile papillomas $(n=3)$, lobomycosis $(n=2)$, and nonspecific dermatitis $(n=2)$. Interestingly, 1 dolphin (982) had a genital papilloma on the first examination that was not present on re-examination 9 yr later.

\section{DISCUSSION}

This is the first long-term study documenting and characterizing the various pathologic diagnoses, prevalence, and progression of mucocutaneous lesions in bottlenose dolphins from the southeastern US. Genital sessile papillomas were the most common mucocutaneous lesions observed in the present study in both IRL and CHS dolphins. These cases were part of a sexually transmitted epidemic that involved adult male and female dolphins at both sites (Bossart et al. 2008, Reif et al. 2008). Papillomavirusassociated orogenital papillomas have been described in other marine mammal species (Van Bressem et al. 1996, 1999, 2007 a, Bossart et al. 2002, Ghim et al. 2014). In our earlier study from 2003 to 2005, orogenital papillomas were described for the first time in association with virions ultrastructurally suggestive of a herpesvirus (Bossart et al. 2005), and later with infection associated with the first reported American dolphin papillomavirus (Rehtanz et al. 2006, 2010). More recently, co-infection with a papillomavirus and herpesvirus was reported in genital papillomas from HERA dolphins (Rehtanz et al. 2012). Furthermore, dolphins with suspected sexually transmitted orogenital papillomas have clinicoimmunopathologic abnormalities consistent with an acute-phase inflammatory response and disturbances in innate and humoral immunity, all possible responses to the tumors and/or the viruses associated with the tumors (Bossart et al. 2008). Thus, the high prevalence of tumors in the present study suggests that orogenital papillomatosis is being maintained in these dolphin populations from continued sexual transmission and that the lesions evade immune surveillance.

Genital papillomas were more common than oral papillomas in the present study. Oral sessile papillomas were found in only 2 IRL dolphins. In contrast, oral papillomas were more prevalent than genital papillomas in dolphins under managed care in an earlier study (Bossart et al. 2005). Interestingly, genital papillomas were also the most common mucocutaneous lesion found in dolphins with multiple lesions biopsied at the same examination. Lesions 
found concurrently with genital papillomas were primarily of known etiology (i.e. lobomycosis and TSD) or suspected infectious etiology (i.e. nonspecific dermatitis). It is possible that localized mucocutaneous and/or systemic immunologic factors play a role in the development of multiple infectious lesions, since immune system perturbations have been reported in IRL dolphins with lobomycosis (Reif et al.2009a), Chlamydiaceae infection (Bossart et al. 2014), and subclinical cetacean morbillivirus infection (Bossart et al. 2011), as well as in dolphins with orogenital papillomas (Bossart et al. 2008). Furthermore, 3 of the 6 dolphins that were re-examined and re-biopsied at different times had persistent genital sessile papillomas at 1, 3, and $7 \mathrm{yr}$ following initial biopsy. Genital papilloma persistence also suggests that the tumors can evade effective immune surveillance, possibly due to changes in immune function resulting from viral infection. Immunosuppression associated with papillomavirus infection was previously implicated in the pathogenesis of cutaneous and mucosotropic papillomatosis in other species, including manatees and humans (Harwood et al. 2000, Bossart et al. 2002, Palefsky 2006, 2007, Donà et al. 2011, Ghim et al. 2014). Alternatively, genital papilloma disappearance in 1 dolphin suggests an immunologic response that effectively eliminated the tumor as recently described in a Florida manatee (Ghim et al. 2014) and occurs in domestic animals (Nicholls \& Stanley 2000, MacLachlan \& Kennedy 2002). Finally, a previous study suggested that malignant transformation of sessile papillomas to squamous cell carcinoma can occur in some dolphins (Bossart et al. 2005). In humans, some papillomavirus types, particularly those found in mucosotropic lesions of the oropharynx and genital tract, can be associated with malignant transformation (zur Hausen 2009). However, no evidence of malignancy was observed in the dolphins from the present study.

Lobomycosis (lacaziosis), the second most prevalent lesion, is caused by the uncultivable onygenale fungus Lacazia loboi and is endemic in the IRL dolphin population (Reif et al. 2006, 2013, Murdoch et al. 2008). HERA dolphins with lobomycosis were reported to have multiple defects in adaptive immunity (Reif et al. 2009a). Compared to healthy dolphins, affected dolphins had reduced numbers of circulating helper $\mathrm{T}$ cells and mature and immature $\mathrm{B}$ cells as well as a reduction in the number of cells expressing major histocompatibility complex class II molecules. Mitogen-induced lymphocyte proliferation of $\mathrm{T}$ and $\mathrm{B}$ cells was reduced substantially. Changes in lymphocyte surface markers and prolifer- ation were accompanied by reduced antibody titers to common marine microorganisms. The data from the present study suggest that lobomycosis remains endemic in IRL dolphins and does not occur in CHS dolphins. Additionally, the findings suggest that immunologic perturbations continue to be involved in disease pathogenesis, although it remains unclear whether infection with Lacazia represents an opportunistic infection or whether infection leads to secondary changes in immune function (Reif et al. 2013).

TSD conformed to the gross and microscopic morphology well-described for this lesion in many species of free-ranging and managed-care cetaceans worldwide (Geraci et al. 1979, Van Bressem et al. 1993, 1999, 2003, 2006, 2009a,b, 2014, Bracht et al. 2006). TSD is a poxvirus dermatopathy proposed to be caused by a new genus of Cetaceanpoxvirus most closely related to members of the Orthopoxvirus genus with different cetacean lineages (Bracht et al. 2006, Blacklaws et al. 2013). Clinical and epidemiological data indicate that poxvirus infection in odontocetes does not cause a high mortality rate when endemic, although it may kill neonates and calves without protective immunity (Van Bressem et al. 1999, 2003, 2009a,b). Stress, climate events, degraded environmental conditions, and compromised general health appear to play a major role in the clinical manifestation of TSD (Geraci et al. 1979, Van Bressem et al. 2009a,b, 2014, Fury \& Reif 2012). TSD was previously reported in stranded IRL dolphins and speculated to be related to prolonged physiologic or pathologic stressors (Bossart et al. 2003). Additionally, it was previously suggested that TSD may be a general indicator of cetacean population health and that the high prevalence of TSD in some adult odontocete populations reflects a depressed immune system (Van Bressem et al. 2009b). As noted above, previous HERA studies have documented immunologic perturbations in IRL dolphins with various infectious diseases which may further predispose this population to TSD. Furthermore, IRL dolphins are highly exposed to mercury, which also may be immunosuppressive (Reif et al. 2009b, Schaefer et al. 2014).

Nonspecific dermatitis consisted of randomly distributed, superficial, chronic to chronic-active inflammatory lesions of undetermined etiology. Concurrent epidermal hyperplasia was seen in most of the cases. In other species, many chronic dermatoses have features of chronic hyperplastic dermatitis, and thus this reaction is not highly specific (Gross et al. 2005, Ginn et al. 2007). It is possible that these lesions were caused by multiple unrelated noninfectious or 
infectious etiologies, the latter not apparent or undetectable with the techniques used in the study. The dermatitides observed may have been traumatic in origin resulting from intra-specific interactions, shark predation, fishery, and/or other human-related activities which are common in dolphins (Murdoch et al. 2008, Bechdel et al. 2009). Alternatively, the cutaneous lesions may have been secondary to already compromised health as described for HERA dolphins (Reif et al. 2008) as well as for stranded Florida dolphins with multisystemic disease (Bossart et al. 2003, 2013).

The etiology of epidermal hyperplasia was undetermined. In other species, epidermal hyperplasia is a common and ubiquitous characteristic of chronic noninflammatory skin diseases of many unrelated causes associated with internal factors (e.g. hormonal, metabolic, genetic) and external injury (e.g. trauma) (Gross et al. 2005). Epidermal hyperplasia is a common feature of many chronic inflammatory processes and thus was likely multifactorial in the present study. It may have represented a resolving end stage of nonspecific dermatitis since epidermal hyperplasia was usually a component of these inflammatory dermatitides.

Dolphins that inhabit the CHS and IRL ecosystems have high site fidelity (Zolman 2002, Mazzoil et al. 2005, Speakman et al. 2010) and are therefore a representative sentinel species for monitoring spatial and temporal trends of environmental health (Wells et al. 2004, Bossart 2011). Both the IRL and CHS ecosystems have experienced significant environmental challenges in the past decade. The estuarine waters around CHS are impacted by rapid urban, industrial, seaport, and residential development with exposures to traditional and emerging environmental contaminants (Adams et al. 2008). Conversely, the IRL is surrounded by a rural and agricultural region which has undergone substantial water quality degradation in recent years. The IRL ecosystem is impacted by agricultural run-off and freshwater intrusion resulting in lower salinity, sediment loading, increased concentrations of nitrogen and phosphorus, loss of sea grass habitat, and exposure to agricultural pesticides (Woodward-Clyde Consultants 1994, Sigua et al. 2000, Sime 2005, Reif et al. 2009a). Additionally, the IRL experienced unusual dolphin mortality events of unknown etiology in 2001, 2008, and 2013 (www. nmfs.noaa.gov/pr/health/mmume/) that may also be directly or indirectly related to declining ecosystem function.

In past studies, environmental and anthropogenic factors were considered to play a role in the preva- lence and severity of cutaneous diseases in cetaceans (Wilson et al. 1999, Bossart 2007, Van Bressem et al. 2007b, 2009a). Similar factors may have played a role in the pathogenesis, diversity, and prevalence of mucocutaneous lesions in the present study. For example, dolphins from both the IRL and CHS accumulate a wide array of anthropogenic contaminants including mercury, polychlorinated biphenyls (PCBs), dichlorodiphenyltrichloroethane (DDT), chlordane, polybrominated diphenylethers (PBDEs), and perfluorinated chemicals (PFCs) (Houde et al. 2005, Stavros et al. 2007, 2008, Fair et al. 2010, 2012, 2013, Schaefer et al. 2011, 2014). CHS dolphins accumulate a suite of persistent organic chemicals at or above the level where adverse health effects have been reported in wildlife, humans, and laboratory animals (Fair et al. 2010). In IRL dolphins, concentrations of mercury in the blood and skin are reported to be among the highest observed in marine mammals and more than 4 times higher than those found in dolphins sampled in CHS (Stavros et al. 2007, 2008). Elevated mercury concentrations in IRL dolphins are associated with disturbances of multiple hepatic, renal, endocrine, and hematological parameters suggesting deleterious health effects (Schaefer et al. 2011). Additionally, other anthropogenic factors in the IRL and CHS, such as increased recreational boating and fishery-related interactions (Noke \& Odell 2002, Burdett \& McFee 2004), may play a role in the nonspecific dermatitides observed. Furthermore, past studies indicate that the IRL dolphin population, in particular, is impacted by complex infectious or inflammatory diseases often associated with concurrent immunologic perturbations (Reif et al. 2006, 2008, 2009a, 2013, Bossart et al. 2010, 2011, 2014, Goldstein et al. 2012). Indeed, the high prevalence of mucocutaneous lesions in IRL dolphins may reflect chronic exposure to these various stressors. The intricate dynamic interactions between various infectious agents and environmental factors further complicate our understanding of the pathogenesis of mucocutaneous disease in dolphins. Additional research is needed to determine the causes and impacts of these diseases on the general health of dolphins and their relationship to ecosystem health.

Acknowledgements. The Atlantic bottlenose dolphin HERA project is a collaborative effort between Georgia Aquarium, Harbor Branch Oceanographic Institute at Florida Atlantic University, and the National Ocean Service, Center for Coastal Environmental Health and Biomolecular Research, NOAA. Support was provided by the Florida Protect Wild Dolphins specialty license plate program, Georgia Aquarium, and the NOAA Fisheries Marine Mammal Health and 
Stranding Response Program. We thank the entire HERA project staff for their tireless efforts in this project, with special thanks extended to Larry Hansen, Dr. Forrest Townsend, and Wayne McFee.

\section{LITERATURE CITED}

Adams J, Houde M, Muir D, Bossart GD, Fair PA (2008) Land use and the spatial distribution of perfluoroalkyl compounds as measured in the plasma of bottlenose dolphin (Tursiops truncatus). Mar Environ Res 66:430-437

> Bearzi M, Rapoport S, Chau J, Saylan C (2009) Skin lesions and physical deformities of coastal and offshore common bottlenose dolphins (Tursiops truncatus) in Santa Monica Bay and adjacent areas, California. Ambio 38:66-71

> Bechdel SE, Mazzoil MS, Murdoch ME, Howells EM and others (2009) Prevalence and impacts of motorized vessels on bottlenose dolphins (Tursiops truncatus) in the Indian River Lagoon, Florida. Aquat Mamm 35:367-377

Blacklaws BA, Gajda AM, Tippelt S, Jepson PD Deaville R, Van Bressem MF, Pearce GP (2013) Molecular characterization of poxviruses associated with tattoo skin lesions in UK cetaceans. PLoS ONE 8:e71734

Bossart GD (2007) Emerging diseases in marine mammals: from dolphins to manatees. Microbe 2:544-549

> Bossart GD (2011) Marine mammals as sentinel species of ocean and human health. Vet Pathol 48:676-690

Bossart GD, Ewing R, Lowe M, Sweat M and others (2002) Viral papillomatosis in Florida manatees (Trichechus manatus latirostris). Exp Mol Pathol 72:37-48

Bossart GD, Meisner R, Varela R, Mazzoil M and others (2003) Pathologic findings in stranded Atlantic bottlenose dolphins (Tursiops truncatus) from the Indian River Lagoon, Florida. Fla Sci 66:226-238

> Bossart GD, Ghim S, Rehtanz M, Goldstein J and others (2005) Orogenital neoplasia in Atlantic bottlenose dolphins (Tursiops truncatus). Aquat Mamm 31:473-480

Bossart GD, Goldstein JD, Murdoch EM, Fair PA, McCulloch S (2006) Health assessment of bottlenose dolphins in the Indian River Lagoon, Florida and Charleston, South Carolina. Tech Rep 93. Harbor Branch Oceanographic, Ft. Pierce, FL

Bossart GD, Romano TA, Peden-Adams MM, Rice CD and others (2008) Hematological, biochemical and immunological findings in Atlantic bottlenose dolphins (Tursiops truncatus) with orogenital papillomas. Aquat Mamm 34: 166-177

Bossart GD, Reif JS, Schaefer AM, Goldstein J, Fair PA, Saliki JT (2010) Morbillivirus infection in free-ranging Atlantic bottlenose dolphins (Tursiops truncatus) from the southeastern United States: seroepidemiologic and pathologic evidence of subclinical infection. Vet Microbiol 143:160-166

Bossart GD, Romano TA, Peden-Adams MM, Schaefer A and others (2011) Clinicoimmunopathologic findings in Atlantic bottlenose dolphins Tursiops truncatus with positive cetacean morbillivirus antibody titers. Dis Aquat Org 97:103-112

Bossart GD, Hurley W, Biedenbach G, Denny M and others (2013) Pathologic findings in stranded cetaceans from northeastern Florida. Fla Sci 76:36-50

> Bossart GD, Romano TA, Peden-Adams MM, Schaefer A and others (2014) Clinicoimmunopathologic findings in Atlantic bottlenose dolphins Tursiops truncatus with pos- itive Chlamydiaceae antibody titers. Dis Aquat Org 108: 71-81

Bracht AJ, Brude RL, Ewing RY, Manire CA and others (2006) Genetic identification of novel poxviruses of cetaceans and pinnipeds. Arch Virol 151:423-438

Burdett LG, McFee WE (2004) Bycatch of bottlenose dolphins in South Carolina, USA and an evaluation of the Atlantic blue crab fishery categorization. J Cetacean Res Manag 6:231-240

> Donà MG, Rehtanz M, Adimey NM, Bossart GD, Jensen AB, Bonde RK, Ghim SJ (2011) Seroepidemiology of TmPV1 infection in captive and wild Florida manatees (Trichechus manatus latirostris). J Wildl Dis 47:673-684

Fair PA, Adams JD, Zolman E, McCulloch S and others (2006) Protocols for conducting dolphin capture release health assessment studies. Tech Memo 49. NOAA NOS NCCOS, Charleston, SC

> Fair PA, Adams J, Mitchum G, Hulsey TC and others (2010) Contaminant blubber burdens in Atlantic bottlenose dolphins (Tursiops truncatus) from two southeast U.S. estuarine areas: concentrations and patterns of PCBs, pesticides, PBDEs, PFCs, and PAHs. Sci Total Environ 408: 1577-1597

Fair PA, Houde M, Hulsey TC, Bossart GD, Adams J, Balthis L, Muir DC (2012) Assessment of perfluorinated compounds (PFCs) in plasma of bottlenose dolphins from two southeast US estuarine areas: relationship with age, sex and geographic locations. Mar Pollut Bull 64:66-74

Fair PA, Romano T, Schaefer AM, Reif JS and others (2013) Associations between perfluoroalkyl compounds and immune and clinical chemistry parameters in highly exposed bottlenose dolphins (Tursiops truncatus). Environ Toxicol Chem 32:736-746

Fury CA, Reif JS (2012) Incidence of poxvirus-like lesions in two estuarine dolphin populations in Australia: links to flood events. Sci Total Environ 416:536-540

Geraci JR, Lounsbury VJ (2005) Marine mammals ashore: a field guide for strandings, $2^{\text {nd }}$ edn. National Aquarium in Baltimore, Baltimore, MD

> Geraci JR, Hicks BD, St Aubin DJ (1979) Dolphin pox: a skin disease of cetaceans. Can J Comp Med 43:399-404

> Ghim S, Joh J, Mignucci-Giannoni AA, Rivera-Guzmán AL and others (2014) Genital papillomatosis associated with two novel mucosotropic papillomaviruses from a Florida manatee (Trichechus manatus latirostris). Aquat Mamm 40:195-200

Ginn PE, Mansell JEKL, Rakich PM (2007) Skin and appendages. In: Maxie MG (ed) Pathology of domestic animals, $5^{\text {th }}$ edn. Saunders Elsevier, Philadelphia, PA, p 553-781

Goldstein JD, Schaefer AS, McCulloch SD, Fair PA, Bossart GD, Reif JS (2012) Clinicopathologic findings from Atlantic bottlenose dolphins (Tursiops truncatus) with cytologic evidence of gastric inflammation. J Zoo Wildl Med 43:730-738

Gross TL, Ihrke PJ, Walder EJ, Affolter VK (2005) Skin diseases of the dog and cat: clinical and histopathologic diagnosis, $2^{\text {nd }}$ edn. Blackwell Science, Oxford

Hart LB, Rotstein DS, Wells RS, Allen J and others (2012) Skin lesions on common bottlenose dolphins (Tursiops truncatus) from three sites in the northwest Atlantic, USA. PLoS ONE 7:e33081

Harwood CA, Surentheran T, McGregor JM, Spink PJ, Leigh IM, Breuer J, Proby CM (2000) Human papillomavirus infection and nonmelanoma skin cancer in 
immunosuppressed and immunocompetent individuals. J Med Virol 61:289-297

> Hohn A, Scott M, Wells R, Sweeney JC, Irvine AB (1989) Growth layers in teeth from free-ranging, known-age bottlenose dolphins. Mar Mamm Sci 5:315-342

Houde M, Wells R, Fair P, Bossart G and others (2005) Polyfluoroalkyl compounds in free-ranging bottlenose dolphins (Tursiops truncatus) from the Gulf of Mexico and the Atlantic Ocean. Environ Sci Technol 39:6591-6598

MacLachlan NJ, Kennedy PC (2002) Tumors of the genital tract. In: Meuten DJ (ed) Tumors in domestic animals, $4^{\text {th }}$ edn. Iowa State University Press Ames, IA, p 547-573

> Maldini D, Riggins J, Cecchetti A, Cotter MP (2010) Prevalence of epidermal conditions in California coastal bottlenose dolphins (Tursiops truncatus) in Monterey Bay. Ambio 39:455-462

Mazzoil M, McCulloch SD, Defran RH (2005) Observations on the site fidelity of bottlenose dolphins (Tursiops truncatus) in the Indian River Lagoon, Florida. Fla Sci 68: 217-227

Mazzoil M, Reif JS, Youngbluth M, Murdoch ME and others (2008) Home ranges of bottlenose dolphins (Tursiops truncatus) in the Indian River Lagoon, Florida: environmental correlates and implications for the management strategies. EcoHealth 5:278-288

Murdoch ME, Reif JS, Mazzoil M, McCulloch SD, Fair PA, Bossart GD (2008) Lobomycosis in bottlenose dolphins (Tursiops truncatus) from the Indian River Lagoon, Florida: estimation of prevalence, temporal trends and spatial distribution. EcoHealth 5:289-297

Nicholls PK, Stanley MA (2000) The immunology of animal papillomaviruses. Vet Immunol Immunopathol 73: 101-127

Noke WD, Odell D (2002) Interactions between the Indian River Lagoon blue crab fishery and the bottlenose dolphin (Tursiops truncatus). Mar Mamm Sci 18:819-832

Palefsky J (2006) HPV infection and HPV-associated neoplasia in immunocompromised women. Int $\mathrm{J}$ Gynaecol Obstet 94:S56-S64

Palefsky J (2007) Human papillomavirus infection in HIVinfected persons. Top HIV Med 15:130-133

Rehtanz M, Ghim SJ, Rector A, Van Ranst M, Fair P, Bossart GD, Jenson AB (2006) Isolation and characterization of the first American bottlenose dolphin papillomavirus: Tursiops truncatus papillomavirus type 2. J Gen Virol 87: 3559-3565

- Rehtanz M, Ghim SJ, McFee W, Doescher B and others (2010) Papillomavirus antibody prevalence in free-ranging and captive bottlenose dolphins (Tursiops truncatus). J Wildl Dis 46:136-145

> Rehtanz M, Bossart GD, Fair PA, Ghim S, Reif JS, Jenson AB (2012) Papillomaviruses and herpesviruses: Who is who in genital tumor development of free-ranging Atlantic bottlenose dolphins (Tursiops truncatus)? Vet Microbiol 160:297-304

> Reif JS, Mazzoil M, McCulloch SD, Varela RA, Goldstein JD, Fair PA, Bossart GD (2006) Lobomycosis in Atlantic bottlenose dolphins (Tursiops truncatus) from the Indian River Lagoon, Florida. J Am Vet Med Assoc 228:104-108

- Reif JS, Fair PA, Adams J, Joseph B and others (2008) Evaluation and comparison of the health status of Atlantic bottlenose dolphins from the Indian River Lagoon, Florida, and Charleston, South Carolina. J Am Vet Med Assoc 233:299-307

Reif JS, Peden-Adams MM, Romano TA, Rice CD, Fair PA,
Bossart GD (2009a) Immune dysfunction in Atlantic bottlenose dolphins (Tursiops truncatus) with lobomycosis. Med Mycol 47:125-135

Reif JS, Schaefer A, Stavros AC, Peden-Adams MM and others (2009b) Bottlenose dolphins as sentinels for exposure to mercury: effects on immune function. Abstracts of the $18^{\text {th }}$ Biennial Conference on the Biology of Marine Mammals, Québec City, Canada, Oct. 12-16

> Reif JS, Schaefer AM, Bossart GD (2013) Lobomycosis: risk of zoonotic transmission from dolphins to humans. Vector Borne Zoonotic Dis 13:689-693

> Schaefer AM, Stavros HW, Bossart GD, Fair PA, Reif JS (2011) Effects of mercury on hepatic, renal, endocrine and hematological parameters in Atlantic bottlenose dolphins (Tursiops truncatus) along the eastern coast of Florida and South Carolina. Arch Environ Contam Toxicol 61:688-695

Schaefer AM, Jensen EL, Bossart GD, Reif JS (2014) Hair mercury concentrations and fish consumption patterns in Florida residents. Int $\mathrm{J}$ Environ Res Public Health 11: 6709-6726

Sigua GC, Steward JS, Tweedale WA (2000) Water-quality monitoring and biological integrity assessment in the Indian River Lagoon, Florida: status, trends, and loadings (1988-1994). Environ Manag 25:199-209

Sime P (2005) St. Lucie Estuary and Indian River Lagoon conceptual ecological model. Wetlands 25:898-907

Speakman TR, Lane SM, Schwacke LH, Fair PA, Zolman ES (2010) Mark-recapture estimates of seasonal abundance and survivorship for bottlenose dolphins (Tursiops truncatus) near Charleston, South Carolina. J Cetacean Res Manag 11:153-162

> Stavros HC, Bossart GD, Hulsey TC, Fair PA (2007) Trace element concentrations in skin of free-ranging bottlenose dolphins (Tursiops truncatus) from the southeast Atlantic coast. Sci Total Environ 388:300-315

> Stavros HC, Bossart GD, Hulsey TC, Fair PA (2008) Trace element concentrations in blood of free-ranging bottlenose dolphins (Tursiops truncatus): influence of age, sex and location. Mar Pollut Bull 56:371-379

Van Bressem MF, Van Waerebeek K, Reyes JC, Dekegel D, Pastoret PP (1993) Evidence of poxvirus in dusky dolphin (Lagenorhynchus obscurus) and Burmeister's porpoise (Phocoena spinipinnis) from coastal Peru. J Wildl Dis 29: 109-113

> Van Bressem MF, Van Waerebeek K, Piérard GE, Desaintes C (1996) Genital and lingual warts in small cetaceans from coastal Peru. Dis Aquat Org 26:1-10

Van Bressem MF, Van Waerebeek K, Raga JA (1999) A review of virus infections of cetaceans and the potential impact of morbilliviruses, poxviruses and papillomaviruses on host population dynamics. Dis Aquat Org 38:53-65

> Van Bressem MF, Gaspar R, Aznar FJ (2003) Epidemiology of tattoo skin disease in bottlenose dolphins Tursiops truncatus from the Sado estuary, Portugal. Dis Aquat Org 56:171-179

Van Bressem MF, Van Waerebeek K, Bennett M (2006) Orthopoxvirus neutralising antibodies in small cetaceans from the Southeast Pacific. Lat Am J Aquat Mamm 5:49-54

> Van Bressem MF, Cassonnet P, Rector A, Desaintes C and others (2007a) Genital warts in Burmeister's porpoises: characterization of Phocoena spinipinnis papillomavirus type 1 (PsPV-1) and evidence for a second, distantly related PsPV. J Gen Virol 88:1928-1933

Van Bressem MF, Van Waerebeek KV, Reyes JC, Félix F and 
others (2007b) A preliminary overview of skin and skeletal diseases and traumata in small cetaceans from South American waters. Lat Am J Aquat Mamm 6:7-42

Van Bressem MF, Raga JA, Di Guardo G, Jepson PD and others (2009a) Emerging infectious diseases in cetaceans worldwide and the possible role of environmental stressors. Dis Aquat Org 86:143-157

Van Bressem MF, Van Waerebeek KV, Aznar FJ, Raga JA and others (2009b) Epidemiological pattern of tattoo skin disease: a potential general health indicator for cetaceans. Dis Aquat Org 85:225-237

Van Bressem MF, Minton G, Collins T, Willson A, Baldwin R, Van Waerebeek K (2014) Tattoo-like skin disease in the endangered subpopulation of the humpback whale, Megaptera novaeangliae, in Oman (Cetacea: Balaenopteridae). Zool Middle East 61:1-8

Wells RS, Rhinehardt HL, Hansen LJ, Sweeney JC and others (2004) Bottlenose dolphins as marine ecosystem sentinels: developing a health monitoring system. Eco-

Editorial responsibility: Michael Moore,

Woods Hole, Massachusetts, USA
Health 1:246-254

Wilson B, Arnold H, Bearzi G, Fortuna CM and others (1999) Epidermal diseases in bottlenose dolphins: impacts of natural and anthropogenic factors. Proc R Soc Lond B Biol Sci 266:1077-1083

Wilson B, Grellier K, Hammond PS, Brown G, Thompson PM (2000) Changing occurrence of epidermal lesions in wild bottlenose dolphins. Mar Ecol Prog Ser 205:283-290

Woodward-Clyde Consultants (1994) Biological resources of Indian River Lagoon. Indian River Lagoon National Estuary Program. Final Technical Report. Project No. 92F274C. Woodward-Clyde Consultants, Melbourne, FL

Zolman ES (2002) Residence patterns of bottlenose dolphins (Tursiops truncatus) in the Stono River estuary, Charleston County, South Carolina, USA. Mar Mamm Sci 18:879-892

zur Hausen H (2009) Papillomaviruses in the causation of human cancers - a brief historical account. Virology 384: 260-265

Submitted: April 13, 2015; Accepted: June 11, 2015

Proofs received from author(s): August 6, 2015 